NBER WORKING PAPER SERIES

\title{
HIGH-SKILLED IMMIGRATION, STEM EMPLOYMENT, AND NON-ROUTINE-BIASED TECHNICAL CHANGE
}

\author{
Nir Jaimovich \\ Henry E. Siu \\ Working Paper 23185 \\ http://www.nber.org/papers/w23185 \\ NATIONAL BUREAU OF ECONOMIC RESEARCH \\ 1050 Massachusetts Avenue \\ Cambridge, MA 02138 \\ February 2017
}

We thank David Green, Valerie Ramey, and participants at the Bank of Canada Labour Workshop and NBER Global Talent SI Conference for valuable comments and discussion. Siu thanks the Social Sciences and Humanities Research Council of Canada for support. The views expressed herein are those of the authors and do not necessarily reflect the views of the National Bureau of Economic Research.

NBER working papers are circulated for discussion and comment purposes. They have not been peer-reviewed or been subject to the review by the NBER Board of Directors that accompanies official NBER publications.

(C) 2017 by Nir Jaimovich and Henry E. Siu. All rights reserved. Short sections of text, not to exceed two paragraphs, may be quoted without explicit permission provided that full credit, including $(\odot$ notice, is given to the source. 
High-Skilled Immigration, STEM Employment, and Non-Routine-Biased Technical Change

Nir Jaimovich and Henry E. Siu

NBER Working Paper No. 23185

February 2017

JEL No. E0,J0

\section{$\underline{\text { ABSTRACT }}$}

We study the role of foreign-born workers in the growth of employment in STEM occupations since 1980. Given the importance of employment in these fields for research and innovation, we consider their role in a model featuring endogenous non-routine-biased technical change. We use this model to quantify the impact of high-skilled immigration, and the increasing tendency of such immigrants to work in innovation, on the pace of non-routine-biased technical change, the polarization of employment opportunities, and the evolution of wage inequality since 1980 .

Nir Jaimovich

Department of Finance and Business Economics

Marshall Business School

University of Southern California

Los Angeles, CA 90089-0804

and NBER

nir.jaimovich@marshall.usc.edu

Henry E. Siu

Vancouver School of Economics

University of British Columbia

6000 Iona Drive

Vancouver, BC V6T 1L4

CANADA

and NBER

hankman@mail.ubc.ca 


\section{Introduction}

Immigration has constituted an important source of growth in high-skilled employment, innovation, and productivity in the U.S. during the past 35 years. In this paper, we study the role of this immigration in accounting for changes in the occupational-skill distribution and wage inequality experienced during this time period.

There is a growing body of empirical work studying the labor market implications of highskilled immigration. Most of this work focuses on the impact on employment outcomes for other high-skilled workers and specifically, whether there is "crowding-out" or displacement of the native-born. Though methodological approaches differ across studies, a rough summary of the literature is that there is little or no evidence that such displacement exists. ${ }^{1}$ However, as noted by Kerr (2013), much less is known about the long-run and general equilibrium impacts of high-skilled immigration on the U.S. labor market. The aim of this paper is to contribute on this dimension, and provide a quantitative theoretic framework in which such questions can be addressed.

The starting point of our analysis, as documented in Section 2 and by Hanson and Slaughter (2016), is the fact that high-skilled immigrants represent a large and growing share of employment in STEM occupations - fields related to research, development, and innovation which are key to productivity growth and technological progress. As such these high-skilled immigrants and foreign-born innovators contribute disproportionately to U.S. growth. As we show in Section 2, the likelihood of high-skilled immigrants to work in a STEM occupation has increased over time, while this likelihood has remained essentially constant for the native-born. This differential change is not due simply to differences in demographic change between native- and foreign-born workers; rather, relative to native-born high-skilled workers, the foreign-born have either experienced a much larger change in their propensity to work in STEM occupations conditional on demographic characteristics, or there has been an important change in unobservable characteristics of the foreign-born, or both.

During the same time of increased high-skilled immigration, the economy has experienced technical change that is non-routine-biased, allowing technology to substitute for labor in performing "routine tasks" during the past 35 years. ${ }^{2}$ Given this, we present in Section 3 a unified framework of endogenous non-routine-biased technical change (NBTC, hereafter) with both native- and foreign-born workers. In the model workers face an occupational choice between

\footnotetext{
${ }^{1}$ See Hunt and Gauthier-Loiselle (2010), Kerr and Lincoln (2010), and Peri et al. (2015). Kerr (2013) provides a very useful overview of the literature on immigration, high-skilled labor markets, and innovation.

${ }^{2}$ While others have referred to this process as "routine-biased" technical change (see, for instance, Goos et al. (2014) and Autor et al. (2015)), we depart from the literature and use the term non-routine-biased. This is in keeping with the use of terminology in the literature on skill-biased technical change (see, for instance, Violante (2008)), in which recent technological progress has benefited skilled (versus unskilled) workers. As argued here and in the literature on job polarization (discussed below), recent technical change has benefited workers in non-routine (versus routine) occupations.
} 
employment in production or innovation jobs. As such, NBTC is the outcome of purposeful activity, namely the equilibrium allocation of workers to innovation. These elements of the model allow us to present a framework to assess the general equilibrium implications of high-skilled immigration and changes in occupational sorting documented in Section 2.

In Section 4, we discuss the calibration and quantitative specification of the model. We then use the model to quantify the role of high-skilled immigration on non-routine-biased technical change, its associated polarization of employment opportunities, and the evolution of wage inequality since 1980. We find that, contrary to expectation, high-skilled immigration has contributed to a narrowing of wage inequality.

\section{Empirical Facts}

\subsection{Immigration and High-Skilled Employment}

According to the U.S. Census Bureau, the foreign-born share of the population has more than doubled between 1980 and 2010, from 6.2\% to 12.9\% (see Grieco et al. (2012)). As a result, the foreign-born share of high-skilled employment has increased as well. In Table 1, we present evidence of this using the $5 \%$ sample of the 1980 decennial census and the $1 \%$ sample of the 2010 American Community Survey (ACS), made available by IPUMS (see Ruggles et al. (2010)). We restrict attention to the 20-64 year old (or "working age") population. Given differences in the questionnaire, we define high-skilled workers as those with at least four years of college in the 1980 census, and those with at least a Bachelor's degree in the 2010 ACS. ${ }^{3}$

Evidently, high-skilled, foreign-born employment increased by 5.7 million workers during this period. As a fraction of total high-skilled employment (in levels), the foreign-born share increased from $7.8 \%$ in 1980 to $16.8 \%$ in 2010 , mirroring the proportional increase in the overall population. The bottom row of Column 1, Table 1 indicates that, of the total growth in highskilled employment, approximately $23 \%$ is accounted for by the foreign-born.

Employment of high-skilled workers is highly concentrated within certain occupations. To illustrate this, we adopt the classification system used in the job polarization literature that documents changes in the occupational employment distribution since the 1980s (see, for instance, Acemoglu and Autor (2011) and Cortes et al. (2015)). We delineate occupations along two dimensions - "cognitive" versus "manual," and "routine" versus "non-routine" — based on the skill content of tasks performed on the job. The distinction between cognitive and manual jobs is based on the extent of mental versus physical activity. The distinction between routine and non-routine occupations is based on the work of Autor et al. (2003). If the tasks involved can be

\footnotetext{
${ }^{3}$ For highly related results to those presented in this subsection and the next, see Hanson and Slaughter (2016) who provide more detailed analysis disaggregated by educational attainment and occupation, analysis of wages and earnings, and discussion on the H1-B visa program and means of entry.
} 
Table 1: High-Skilled Employment by Occupational Group

\begin{tabular}{lcccccc}
\hline \hline & \multicolumn{2}{c}{1. Total } & \multicolumn{2}{c}{ 2. NRC } & \multicolumn{2}{c}{ 3. STEM } \\
& 1980 & 2010 & 1980 & 2010 & 1980 & 2010 \\
\hline foreign-born & 1,368 & 7,061 & 951 & 4,948 & 172 & 1,063 \\
native-born & 16,283 & 34,973 & 11,933 & 25,256 & 1,238 & 2,653 \\
& & & & & & \\
foreign-born share & & & & & & \\
$\quad$ employment & 0.078 & 0.168 & 0.074 & 0.164 & 0.122 & 0.286 \\
employment growth & $23.3 \%$ & $23.1 \%$ & $38.6 \%$ \\
\hline \hline
\end{tabular}

Notes: Employment among 20-64 year olds with $\geq 4$ years of college/bachelor's degree, in thousands. Data from 1980 Census and 2010 American Community Survey. See text for details.

summarized as a set of specific activities accomplished by following well-defined instructions and procedures, the occupation is considered routine. If instead the job requires mental or physical flexibility, problem-solving, or human interaction skills, the occupation is non-routine.

High-skilled employment is concentrated in non-routine cognitive (NRC) occupations. Not surprisingly, these jobs occupy the upper tail of the occupational wage distribution (see, for instance, Goos and Manning (2007) and Acemoglu and Autor (2011)). This is true of both native- and foreign-born workers. The second set of columns of Table 1 display these employment figures. ${ }^{4}$ Among the foreign-born, $951 \div 1368=69.5 \%$ of high-skilled individuals worked in a non-routine cognitive occupation in 1980. This has held remarkably constant over time, at $70.1 \%$ in 2010. Similarly, approximately $72 \%$ of high-skilled native-born workers work in such occupations in both 1980 and $2010 .^{5}$

This occupational concentration, coupled with increasing immigration, implies that the foreign-born share of non-routine cognitive employment has risen over time. This share increased from $7.4 \%$ in 1980 to $16.4 \%$ in 2010, mirroring the proportional increase observed in high-skilled employment and population. Of the total increase in non-routine cognitive employment, approximately $23 \%$ is accounted for by the foreign-born.

While the sorting of high-skilled workers into non-routine cognitive occupations is similar between the native- and foreign-born, sorting into jobs within this occupational group differ in important ways. High-skilled foreign-born workers tend to work in occupations with a quantitative emphasis, whereas the native-born specialize in occupations emphasizing communication and inter-personal skills (see, for instance, Chiswick and Taengnoi (2007), Hunt and Gauthier-

\footnotetext{
${ }^{4}$ In our analysis, non-routine cognitive jobs correspond to those under the categories of management, business and financial operations, and professional occupations in the 2010 Standard Occupational Classification. See Cortes et al. (2015) for a more detailed discussion, as well as how occupation codes are linked across the 1980 and 2010 classification systems.

${ }^{5}$ Perhaps unsurprisingly, the $\approx 30 \%$ of the high-skilled not working in NRC jobs is concentrated in the young. For instance, the fraction of 20-24 year old high-skilled workers employed in a non-routine cognitive occupation is only $57 \%$.
} 
Loiselle (2010), and Peri and Sparber (2011)). This is evident in the native- and foreign-born representation in the subset of non-routine cognitive occupations related to STEM fields: science, technology, engineering, and mathematics, displayed in third set of columns of Table $1 .{ }^{6}$

While the foreign-born accounted for $7.4 \%$ of employment in non-routine cognitive jobs in 1980, they represented $12.2 \%$ of employment in STEM occupations. In 2010, high-skilled foreignborn workers account for $28.6 \%$ of STEM employment, an increase of a factor of approximately 2.5. Of the total increase in STEM employment in the U.S. between 1980 and 2010, approximately $39 \%$ is accounted for by the foreign-born (see also Kerr and Lincoln (2010)). ${ }^{7}$ Finally, as discussed in the literature, such occupations are closely related to innovation and R\&D; as such, high-skilled immigration has played an important role in the output of these occupations as indicated by statistics on patenting, high-tech start-ups, and other measures (see, for instance, Hunt and Gauthier-Loiselle (2010), Hunt (2011), Peri (2012), Kerr (2013), and the references therein).

\subsection{Nativity Differences in STEM Employment}

In this subsection, we take a closer look at occupational sorting among high-skilled workers. Our interest is in the tendency to work in STEM occupations - how this differs between the nativeand foreign-born, and how this difference has changed over time. Panel A of Table 2 presents the fraction of high-skilled workers who are employed in a STEM occupation; Panel B presents the fraction, conditional on being employed in a non-routine cognitive occupation. The basic data are taken from Table 1.

From the perspective of nativity, it is clear that the foreign-born are more likely to work in STEM occupations than native-born. For instance, the fraction of high-skilled workers employed in STEM is 5.0 percentage points greater in 1980 (12.6\% versus 7.6\%); similarly, conditional on being a non-routine cognitive worker, the likelihood of being a STEM worker is 7.7 pp greater. As a point of comparison, the tendency for high-skilled workers born in either India or China to work in STEM is approximately three times that of the native-born.

Over time this difference has become more pronounced. Consider the tendency of the highskilled to work in STEM, conditional on either employment in any occupation, or in a non-routine cognitive occupation. As the third column in Table 2 makes clear, this tendency has remained essentially constant for the native-born between 1980 and 2010. By contrast, the fraction of foreign-born workers in STEM has increased by $2.5 \mathrm{pp}$ in Panel A, and $3.4 \mathrm{pp}$ in Panel B. As such, the foreign-born tendency toward STEM employment is now twice that of native-born workers. $^{8}$

\footnotetext{
${ }^{6}$ In particular, we define STEM jobs as those listed under computer and mathematical, architecture and engineering, and life and physical science occupations, a subset within the professional occupation category.

${ }^{7}$ Interestingly, about $21 \%$ of the total increase in STEM employment in the U.S. is accounted for by the source countries of India and China alone.

${ }^{8}$ See also Peri and Sparber (2011) who find that the occupational choice among native-born "job switchers"
} 
Table 2: High-Skilled Employment in STEM Occupations

\begin{tabular}{lcccc}
\hline \hline & 1980 & 2010 & change & unexplained \\
\hline $\begin{array}{c}\text { A. per worker (\%) } \\
\text { native-born }\end{array}$ & 7.6 & 7.6 & +0.0 & +0.4 \\
foreign-born & 12.6 & 15.1 & +2.5 & +5.3 \\
$\quad$ India \& China & 23.6 & 30.6 & +7.0 & +13.7 \\
\hline B. per NRC worker (\%) & & & & \\
$\quad$ native-born & 10.4 & 10.5 & +0.1 & +1.1 \\
$\quad$ foreign-born & 18.1 & 21.5 & +3.4 & +7.2 \\
$\quad$ India \& China & 30.5 & 38.0 & +7.5 & +13.0 \\
\hline \hline
\end{tabular}

Notes: Employment among 20-64 year olds with $\geq 4$ years of college/bachelor's degree, in thousands. Data from 1980 Census and 2010 American Community Survey. See text for details.

This differential change in tendency is not due simply to differences in demographic change between native- and foreign-born workers. To see this, let $\pi_{i t}$ be a dummy variable that takes on the value of 1 if individual $i$ works in a STEM occupation and 0 otherwise (conditional on either employment or employment in a non-routine cognitive job). We consider a simple linear probability model for working in STEM:

$$
\pi_{i t}=X_{i t} \beta+\epsilon_{i t}
$$

for $t \in\{1980,2010\}$. Here, $X_{i t}$ denotes standard demographic characteristics of individual $i$ observed in the Census and ACS: age, gender, marital status, and an indicator for whether the worker has greater than college education. ${ }^{9}$ The fractions of STEM workers presented in the first two columns of Table 2 are simply the sample averages:

$$
\frac{1}{N} \sum_{i}^{N} \pi_{i t}=\bar{\pi}_{t} .
$$

As such, the change in tendency reported in the third column of Table $2, \bar{\pi}_{2010}-\bar{\pi}_{1980}$, can be decomposed into a component that is "explained" by differences in observables, and an "unexplained" component owing to changes in coefficients, $\beta$, over time (see Oaxaca (1973) and Blinder (1973)). We perform this Oaxaca-Blinder decomposition separately for the native- and foreign-born samples.

The final column of Table 2 presents the estimated unexplained component. ${ }^{10}$ In all cases, the

is affected by the foreign-born worker share. This is consistent with our findings on differential trends in sorting into STEM, and Kerr et al. (2013) who study the impact of skilled immigrants on the employment structures of U.S. firm.

${ }^{9}$ That is, we control for whether the worker has $5+$ years of college in the 1980 Census, and either a Master's, Professional, or Doctoral degree in 2010 the ACS.

${ }^{10}$ We implement this from a pooled regression over both time periods. Results in which coefficient estimates are obtained for either the 1980 or 2010 period are essentially unchanged. 
unexplained component is greater than the actual, observed change. ${ }^{11}$ As a result, the changes observed in the data are not due to the explained component. In addition, as with the observed change in the third column, the native- and foreign-born differ in terms of the magnitude of the unexplained effect. For instance, in Panel A the effect is an order of magnitude larger for the foreign-born. Hence, relative to native-born high-skilled workers, the foreign-born have either experienced a much larger change in their propensity to work in STEM occupations, or there has been an important change in unobservable characteristics of the foreign-born, or both. ${ }^{12}$

\subsection{Non-Routine-Biased Technical Change}

As discussed above, STEM occupations are those involved with R\&D, innovation, and technical change. Given this, we discuss in this subsection the fact that technical change since the 1980s as has been non-routine-biased in nature. That is, in the past 30 years, advances in information and communication technology, robotics, and automation, has allowed technology embodied in machinery, equipment, and software to substitute for labor in performing routine tasks. A growing body of literature documents the prevalence of non-routine-biased technical change (NBTC) in the U.S., and other industrialized economies. ${ }^{13}$

This literature argues that the NBTC resulted in a stark change in the occupational-skill distribution of employment. Industrialized economics have experienced job polarization: the labor market has become polarized, with employment share shifting away from middle-skilled, routine occupations, towards both the high- and low-skill tails of the distribution. To illustrate this, Figure 1 replicates a figure from Jaimovich and Siu (2012). Each bar represents the percent change in an occupational group's share of total employment. Over time, the share of employment in high-skill (non-routine cognitive) and low-skill (non-routine manual) jobs has been growing. This has been accompanied by a hollowing out of the middle-skill, routine occupations. In 1982, routine occupations accounted for approximately $56 \%$ of total employment; in 2012, this share has fallen to $44 \%$. Hence, according to this literature, NBTC has led to a polarization in employment away from routine, middle-skill occupations toward non-routine cognitive and manual jobs.

\footnotetext{
${ }^{11}$ This is due primarily to the fact that the explained component is dominated by the increasing female share of high-skilled employment. Since men are more likely to work in STEM jobs, this change implies that the contribution of the demographic change is negative.

${ }^{12}$ For instance, conditional on having at least a college education, immigrants' fields of study or college major may have changed (more than among the native-born) over time. Unfortunately, this type of information is not available in the census. Perhaps more importantly, the type of visa with which immigrants first entered the U.S. may have changed since 1980. This is particularly relevant given the expansion of the H1-B visa program. See Hunt (2011) for further discussion.

${ }^{13}$ See, for instance, Autor et al. (2003), Violante (2008), Firpo et al. (2011), Acemoglu and Autor (2011), Goos et al. (2014), Levy and Murnane (2014), and Jaimovich and Siu (2015).
} 
Figure 1: Percent Change in Employment Shares by Occupation Group

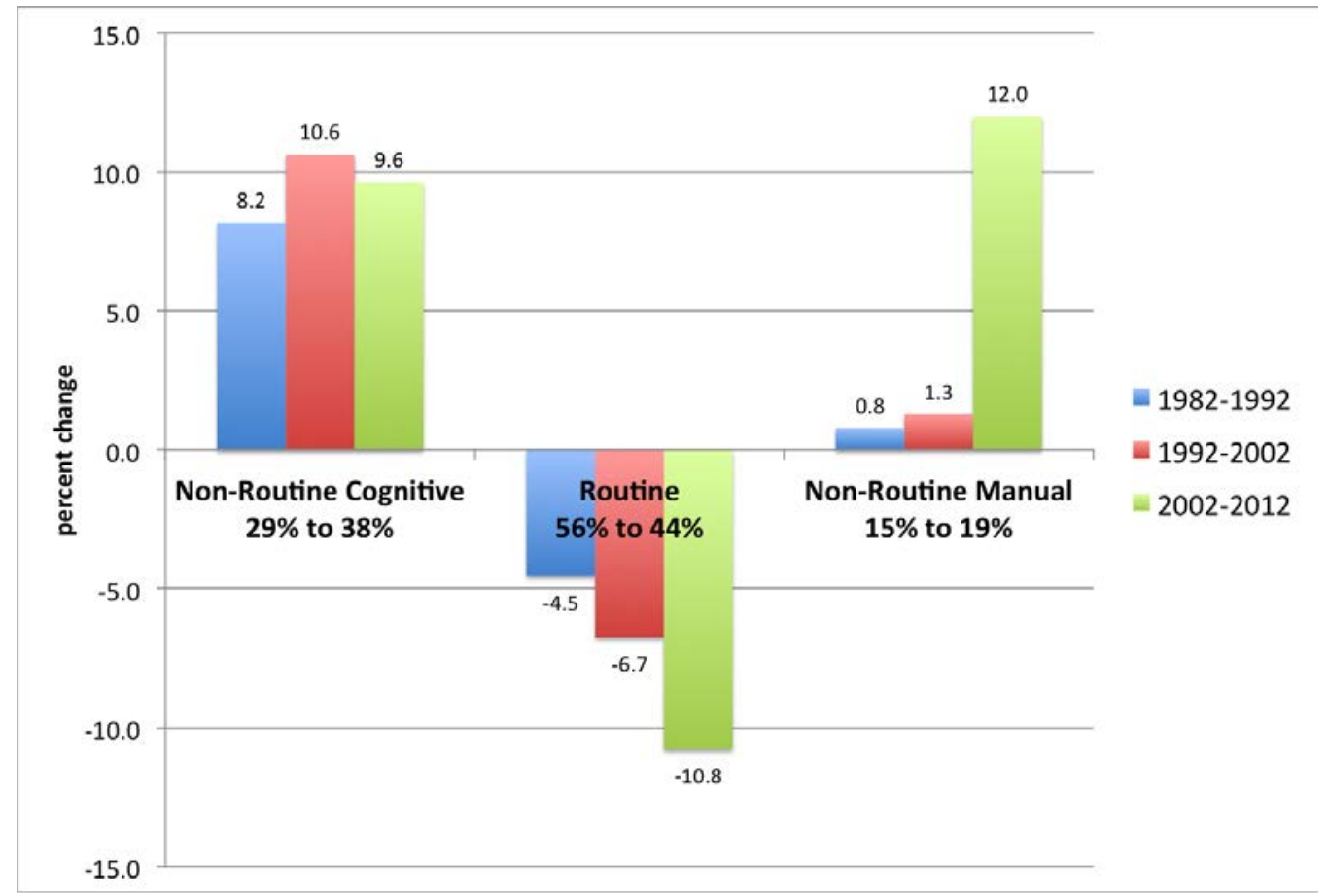

Notes: Data from the Current Population Survey, BLS. See Jaimovich and Siu (2012) for details.

\section{Model}

Motivated by the findings of Section 2, we consider a simple model of endogenous NBTC. Nonroutine-biased technology is modeled as technology that is substitutable with routine labor in production. Advances in this technology are the outcome of employment devoted to innovation activities.

A key element to the model is occupational choice. There are two types of individuals in the economy: low-skilled and high-skilled. Given the data presented in Section 2, high-skilled individuals work in non-routine cognitive occupations. For the sake of exposition, we refer to their choice as either working as innovators (in STEM occupations) in the production of technology, or as managers (in other non-routine cognitive jobs) in the production of goods. Low-skilled individuals choose to work in either routine or service occupations (both of which produce goods).

In Section 4, we use this model to quantify the impact of high-skilled immigration, and the increasing tendency of immigrants to work in innovation, on the pace of NBTC and labor market outcomes. 


\subsection{Production}

Industrial structure The model features three sectors of production. In the first sector, perfectly competitive, price-taking firms produce gross output $(Y)$ using a Cobb-Douglas function in "managerial tasks" and "routine tasks." Managerial tasks are derived from labor input of managers, $L_{M}$. Routine tasks are derived from routine labor input, $L_{R}$, and automation technology, A. Specifically:

$$
Y=\left(z L_{M}\right)^{\alpha}\left[\lambda A^{\rho}+(1-\lambda)\left(z L_{R}\right)^{\rho}\right]^{(1-\alpha) / \rho}, \quad \rho<1 .
$$

Here, $z$ represents labor-augmenting technology, which grows exogenously at the rate $g \geq 0$. By contrast, growth in the automation technology is endogenous to purposeful innovation activities as described below. The degree of substitutability between automation technology and routine labor is governed by $\rho$ : as $\rho \rightarrow 1$, the two factors approach perfect substitutes.

The input of automation technology is composed of intermediate goods, $x_{i}$, with measure $n$, and a fixed factor $\bar{F}$ according to: ${ }^{14}$

$$
A=\bar{F}^{1-\sigma} \int_{0}^{n} x_{i}^{\sigma} d i, \quad 0<\sigma<1 .
$$

We note that this specification of production is related to other work on non-routine-biased technical change. ${ }^{15}$

The second sector produces intermediate goods, $x$. We consider a Romer (1990)-style model in which growth is driven by innovation that expands the variety of intermediate inputs. We assume that the innovator of a specific variety of input owns a permanent patent on the production of its associated intermediate good. Each unit of intermediate good is produced with $\eta$ units of gross output.

In the third sector, perfectly competitive, price-taking firms produce output as a linear function of labor input into service occupations: $L_{S}$ units of service labor input produce $w_{S} L_{S}$ units of output. Finally, to complete the description of production, we note that gross output is either consumed or used as an input in the production of $x$.

Optimization Normalizing the price of output to one, the first-order conditions for profit maximization in the first sector provide expressions for wage rates on managerial and routine

\footnotetext{
${ }^{14}$ The fixed factor is included simply for technical reasons, namely, to ensure that production of $Y$ is homogenous of degree one in factor inputs $L_{M}, L_{R}, \bar{F}$, and $x_{i}$ for all $i \in[0, n]$.

${ }^{15}$ See, for example, Jung and Mercenier (2014) and Acemoglu and Restrepo (2015), as well as Caselli (2015) who studies the effects of experience-biased technical change.
} 
labor, the rental rate on the fixed factor, and the price of intermediate inputs, respectively:

$$
\begin{aligned}
w_{M} & =\alpha Y L_{M}^{-1} \\
w_{R} & =(1-\alpha) Y \Omega(1-\lambda) z^{\rho} L_{R}^{\rho-1} \\
r & =(1-\alpha) Y \Omega \lambda(1-\sigma) \bar{F}^{(1-\sigma) \rho-1}\left[\int_{0}^{n} x_{i}^{\sigma} d i\right]^{\rho} \\
p_{i} & =(1-\alpha) Y \Omega \lambda \bar{F}^{(1-\sigma) \rho}\left[\int_{0}^{n} x_{i}^{\sigma} d i\right]^{\rho-1} \sigma x_{i}^{\sigma-1},
\end{aligned}
$$

where $\Omega=\left[\lambda A^{\rho}+(1-\lambda)\left(z L_{R}\right)^{\rho}\right]^{-1}$.

In the intermediate goods sector, the per period profit earned by the innovator of input variety $i$ is $\pi_{i}=\left(p_{i}-\eta\right) x_{i}$. Substituting in (8), the FOC is given by:

$$
x_{i}=\left(\frac{\sigma \Phi}{\eta}\right)^{\frac{1}{1-\sigma}},
$$

where $\Phi=(1-\alpha) Y \Omega \lambda \bar{F}^{(1-\sigma) \rho}\left[\int_{0}^{n} x_{i}^{\sigma} d i\right]^{\rho-1} \sigma$. In a symmetric equilibrium, denote $x_{i} \equiv x$ for all $i$. Substituting (9) into (8) and the definition of profit yields that the price is a constant markup over marginal cost:

$$
p_{i}=\frac{\eta}{\sigma} \equiv p,
$$

and that profits are given by:

$$
\pi_{i}=(1-\sigma) \Phi^{\frac{1}{1-\sigma}}\left(\frac{\sigma}{\eta}\right)^{\frac{\sigma}{1-\sigma}} \equiv \pi
$$

In the third sector sector, given the linearity of the production function, optimizing behavior implies that the productivity parameter in this sector, $w_{S}$, is equal to the service occupation wage. We assume that $w_{S}$ grows exogenously at the rate $g$.

Differential effects of NBTC Having characterized optimal demand for the various factors of production, we note the following. The marginal product of routine labor $\left(M P L_{R}\right)$ is given by the righthand side of (6). As such:

$$
\operatorname{sgn}\left(\frac{\partial M P L_{R}}{\partial A}\right)=\operatorname{sgn}(1-\alpha-\rho) .
$$

Hence, an increase in automation technology shifts the "demand curve" for routine labor down whenever $\rho>1-\alpha$. Moreover, given the Cobb-Douglas functional form of (3), managerial labor and routine tasks are complementary. Thus, we consider an economy where the effects of automation technology growth are differential: all else equal, it decreases the marginal productivity of routine workers while increasing the marginal productivity of managers. 


\subsection{Households}

The economy is populated by a large, representative household. The household is composed of a continuum of family members, which we refer to as "workers." Each worker supplies one unit of labor inelastically. Within the household, native-born workers are of measure $\mu^{\text {nat }}$, and foreign-born are of measure $\mu^{\text {for }}$. There are two types of native-born workers: high-skilled and low-skilled; we let $\phi$ denote the share of high-skilled native-born. For simplicity, given our interest in high-skilled immigration, we assume that all foreign-born are high-skilled.

Low-skilled workers can be employed in either a routine occupation or a service occupation. Low-skilled workers differ in their routine work ability, $u$, which is distributed $\Upsilon(u)$. By contrast, they are identical in their service occupation ability, which we normalize to unity. Given the date $t$ wage per unit of (effective) routine labor, $w_{R t}$, a worker with ability $u$ earns $u \times w_{R t}$ employed in the routine occupation. Alternatively, workers earn $w_{S t}$ employed in the service occupation, regardless of $u$. Hence, it is optimal for the household to allocate all low-skilled workers with $u<u_{t}^{*}$ to employment in the service occupation, where:

$$
u_{t}^{*} w_{R t}=w_{S t} .
$$

All workers with $u \geq u_{t}^{*}$ are allocated to routine work. We denote $s_{t}^{l o}=\Upsilon\left(u_{t}^{*}\right)$ as the fraction of low-skilled (native-born) workers employed in the service occupation. ${ }^{16}$

High-skilled workers work either as managers or innovators. While they are identical in their ability as managers (which we normalize to unity), high-skilled workers differ in their innovation ability, $a$. This ability is distributed $\Gamma(a)$. For simplicity, we assume this is true of both the native- and foreign-born. A native-born worker with ability $a$ develops $a \times f^{n a t} \times n_{t}$ new ideas at date $t$, to which the innovator's household is bestowed a permanent patent. Here, $f^{n a t}>0$ is a productivity parameter, and $n_{t}$ represents the externality of the aggregate stock of ideas on an individual's innovative activity, as in Romer (1990). Similarly, a foreign-born worker with ability $a$ develops $a \times f^{\text {for }} \times n_{t}$ new ideas.

Alternatively, a high-skilled worker earns $w_{M t}$ employed as a manager, regardless of $a$. It is optimal for the household to allocate all native-born high-skilled workers with $a<a_{t}^{\text {nat* }}$ as managers, where:

$$
\zeta_{t} a_{t}^{n a t *} f^{n a t} n_{t}=\theta_{t} w_{M t} .
$$

Here, $\zeta_{t}$ represents the shadow value to the household of an additional idea, and $\theta_{t}$ the shadow value of an additional unit of income, both of which we derive below. Workers with $a \geq a_{t}^{n a t *}$

\footnotetext{
${ }^{16}$ Note that we have specified workers as supplying labor inelastically; workers do not face a labor-leisure tradeoff, nor do they face the possibility of non-employment. As such, job polarization-generated by our experiments in the following section - is a result of changes in occupational sorting among low-skilled workers. Any decline in routine employment is reflected as a rise in the number of workers allocated to the service occupation. An alternative, would be to introduce an explicit possibility of non-employment for low-skilled workers. See Cortes et al. (2016) for a model of exogenous NBTC where workers choose between non-employment, employment in service jobs, and employment in routine jobs.
} 
are allocated to innovation. Similarly, the cut-off $a_{t}^{f o r *}$ is defined as the value that satisfies:

$$
\zeta_{t} a_{t}^{f o r *} f^{f o r} n_{t}=\theta_{t} w_{M t} .
$$

We denote $s_{t}^{\text {hi }}=\Gamma\left(a_{t}^{\text {nat* }}\right)$ and $s_{t}^{\text {for }}=\Gamma\left(a_{t}^{\text {for* }}\right)$ as the fraction of high-skilled native- and foreignborn workers employed as managers. ${ }^{17}$

The household's date $\tau$ problem is to maximize:

$$
\sum_{t=\tau}^{\infty} \beta^{t-\tau}\left[\int_{0}^{\phi \mu^{n a t}} \log \left(C_{i t}\right) d i+\int_{\phi \mu^{n a t}}^{\mu^{n a t}} \log \left(C_{j t}\right) d j+\int_{\mu^{n a t}}^{\mu^{n a t}+\mu^{f o r}} \log \left(C_{k t}\right) d k\right],
$$

subject to the budget constraint:

$$
\begin{array}{r}
\int_{0}^{\phi \mu^{n a t}} C_{i t} d i+\int_{\phi \mu^{n a t}}^{\mu^{n a t}} C_{j t} d j+\int_{\mu^{n a t}}^{\mu^{n a t}+\mu^{f o r}} C_{k t} d k+B_{t+1} \leq R_{t} B_{t}+r_{t} \bar{F}+m_{t} \pi_{t}+ \\
w_{M t}\left[\mu^{n a t} \phi s_{t}^{h i}+\mu^{f o r} s_{t}^{f o r}\right]+\left[w_{S t} s_{t}^{l o}+w_{R t} \int_{u_{t}^{*}}^{\infty} u d \Upsilon(u)\right] \mu^{n a t}(1-\phi),
\end{array}
$$

and the law-of-motion for the household's stock of patents:

$$
m_{t+1}=m_{t}+n_{t}\left[\mu^{n a t} \phi f^{n a t} \int_{a_{t}^{n a t *}}^{\infty} a d \Gamma(a)+\mu^{\text {for }} f^{\text {for }} \int_{a_{t}^{\text {for* }}}^{\infty} a d \Gamma(a)\right],
$$

for all $t \geq \tau$. In equation (17), $B_{t+1}$ denotes one-period bonds purchased at date $t$ that pay a return of $R_{t+1}$ at date $t+1{ }^{18}$ Rental income on the household's fixed factor is given by $r_{t} \bar{F}$. The second line of (17) denotes household labor income earned by workers in management, service, and routine employment.

At date $t$, the household's stock of ideas is $m_{t}$. With symmetry, each idea earns flow profit $\pi_{t}$. Patents do not expire or depreciate, so that (18) indicates that $m_{t+1}$ is simply the stock today augmented by new ideas developed by high-skilled workers at date $t$.

Let $\theta_{t}$ and $\zeta_{t}$ denote the Lagrange multipliers associated with the date $t$ budget constraint (17) and law-of-motion (18), respectively. Given preferences, optimality involves allocating the same consumption level to all workers, regardless of skill or occupation: $C_{i t}=C_{j t}=C_{k t}=$ $C_{t}, \forall i, j, k$. As such, we note that our model is suited to the analysis of changes in wage and income inequality, as opposed to consumption or welfare inequality. Moreover, optimality implies $\theta_{t}=1 / C_{t}$. The FOC for bond holding is:

$$
\theta_{t}=\beta \theta_{t+1} R_{t+1} .
$$

\footnotetext{
${ }^{17}$ Given that $\Gamma(a)$ is identical across nativity, $f^{n a t} \neq f^{f o r}$ allows the model to generate differences in occupational sorting across high-skilled native- and foreign-born workers; this is made explicit via equation (29) below. An alternative would be to allow the distributions to differ by nativity.

${ }^{18}$ In equilibrium, such bonds are in zero net supply, and simply allow us to designate the household's discount factor in the derivations to follow.
} 
The FOC for the household's stock of ideas is given by:

$$
\zeta_{t}=\beta \zeta_{t+1}+\beta \theta_{t+1} \pi_{t+1}
$$

Iterating forward, this becomes:

$$
\zeta_{t}=\beta \theta_{t+1} \pi_{t+1}+\beta^{2} \theta_{t+2} \pi_{t+2}+\beta^{3} \theta_{t+3} \pi_{t+3}+\ldots
$$

Dividing by $\theta_{t}$ and using (19), obtains:

$$
\frac{\zeta_{t}}{\theta_{t}}=\frac{\pi_{t+1}}{R_{t+1}}+\frac{\pi_{t+2}}{R_{t+1} R_{t+2}}+\frac{\pi_{t+3}}{R_{t+1} R_{t+2} R_{t+3}}+\ldots
$$

As a result, the cut-off condition (14) can be rewritten as:

$$
w_{M t}=a_{t}^{n a t *} f^{n a t} n_{t} \sum_{i=1}^{\infty}\left[\frac{\pi_{t+i}}{\prod_{j=1}^{i} R_{t+j}}\right] .
$$

That is, occupational choice among high-skilled natives is such that, at $a_{t}^{\text {nat* }}$, the return to working as a manager (in terms of current wage income) is equated to the present value of future profit that worker would generate from innovation. Obviously, (15) can be rewritten in the analogous way, with $a_{t}^{\text {for* }} f^{\text {for }}$ replacing $a_{t}^{\text {nat* }} f^{\text {nat }}$ above.

\subsection{Equilibrium and Balanced Growth}

Equilibrium in this model is defined in the usual way. Optimization on the part of firms is summarized by the FOCs (5) through (9). Household optimization is summarized by (13) through (15), and (17) holding with equality.

Since bonds are in zero net supply, $B_{t}=0$. Labor market clearing requires:

$$
\begin{aligned}
L_{S t} & =\mu^{n a t}(1-\phi) s_{t}^{l o}, \\
L_{R t} & =\mu^{n a t}(1-\phi) \int_{u_{t}^{*}}^{\infty} u d \Upsilon(u), \\
L_{M t} & =\mu^{n a t} \phi s_{t}^{h i}+\mu^{f o r} s_{t}^{f o r} .
\end{aligned}
$$

In the ideas market, $m_{t}=n_{t}$. Using (18), this implies that the growth rate of the aggregate stock of ideas is given by:

$$
g_{t+1}^{n}=\frac{n_{t+1}-n_{t}}{n_{t}}=\mu^{n a t} \phi f^{n a t} \int_{a_{t}^{\text {nat* }}}^{\infty} a d \Gamma(a)+\mu^{\text {for }} f^{\text {for }} \int_{a_{t}^{\text {for* }}}^{\infty} a d \Gamma(a) .
$$

Finally, the household budget constraint can be used to derive the aggregate resource constraint:

$$
\left(\mu^{n a t}+\mu^{f o r}\right) C_{t}=Y_{t}+w_{S t} L_{S t}-\eta x_{t} n_{t}
$$


Equation (27) allows us to consider the determinants of the growth of ideas, i.e. non-routinebiased technical change. For instance, an increase in the productivity of innovation, either $f^{\text {nat }}$ or $f^{f o r}$, has a direct effect of increasing $g^{n}$. In addition, such a change has an effect on occupational choice: the more productive is innovation, the lower is the threshold productivity $\left(a^{n a t *}\right.$ and $\left.a^{\text {for* }}\right)$ required to equate returns to managerial work and innovation in (14) and (15), all else equal. Hence, increases in $f^{\text {nat }}$ and $f^{\text {for }}$ have an equilibrium effect of inducing greater resources devoted to innovation that reinforce the direct effect.

In addition, increases in the high-skilled population, either $\mu^{\text {nat }} \phi$ or $\mu^{\text {for }}$, increase NBTC. That is, our model displays a version of the "scale effect" on growth shared by Romer (1990)style models; here, the scale effect is in terms of the measure of high-skilled workers (as opposed to total population per se).

Finally, note that changes in the composition of high-skilled workers affect $g^{n}$ when $a^{n a t *} \neq$ $a^{\text {for* }}$. From equations (14) and (15), it is easy to see that:

$$
\frac{a_{t}^{\text {nat* }}}{a_{t}^{\text {for* }}}=\frac{f^{\text {for }}}{f^{\text {nat }}} .
$$

Suppose, for instance, that $f^{\text {for }}>f^{\text {nat }}$ so $a^{\text {nat* }}>a^{\text {for* }}$; given that the distribution, $\Gamma$, is identical across nativity, this implies that sorting into the innovation occupation is greater among the foreign-born. In this case, a compositional shift toward more foreign-born workers that leaves the total measure of high-skilled workers unchanged has the effect of increasing the growth rate of ideas.

Given this discussion and the characterization of equilibrium, it is possible to consider balanced growth in our economy. In particular, the model admits a balanced growth path (BGP, hereafter) in which labor allocations are constant $\left(u_{t}^{*}=u^{*}, a_{t}^{\text {nat* }}=a^{\text {nat* }}\right.$, and $\left.a_{t}^{\text {for* }}=a^{\text {for* }}\right)$, and the stock of ideas $\left(n_{t}\right)$, labor-augmenting technology $\left(z_{t}\right)$, and the service occupation wage $\left(w_{S t}\right)$ all grow at the same, constant rate $\left(g_{t+1}^{n}=g^{n}=g\right)$. It is straightforward to show that along such a BGP: the service flow $\left(x_{t}\right)$ and profit $\left(\pi_{t}\right)$ from each idea is constant; the gross real interest rate $\left(R_{t}\right)$ is constant; and automation technology $\left(A_{t}\right)$, wages $\left(w_{S t}, w_{R t}, w_{M t}\right)$, and consumption $\left(C_{t}\right)$ grow at rate $g$.

\section{Quantitative Results}

\subsection{Calibration and Parameter Specification}

In this subsection, we discuss the quantification of the model economy to a BGP. This is meant to represent the U.S. economy prior to the onset of job polarization. As such, we view the past 35 years as a period of "unbalanced" growth, characterized by a declining share of employment in routine occupations due to NBTC; we defer discussion of unbalanced growth/NBTC to subsection 4.2 . 
There are 14 parameters that need to be specified. To maintain comparability to the literature, we perform a standard calibration when possible. The initial BGP is calibrated to the U.S. in 1980.

First we normalize $\eta=1$ and $\bar{F}=1$. We then set the BGP growth rate of the technology variables $\left(n, z\right.$, and $\left.w_{S}\right)$ to $2 \%$ per year. To accord with an annual risk-free rate of $4.6 \%$, we set $\beta=0.975$. We set the nativity and skill shares of the employed population to match those observed in the 1980 Census. Normalizing $\mu^{\text {nat }}+\mu^{\text {for }}=1$, we set $\mu^{\text {for }}=0.0137$ to accord with the fraction of high-skilled, foreign-born workers in the economy. Of the native-born, $\phi=0.17$ specifies the split between high- and low-skilled workers.

To match the fat right-tail of returns to innovation and entrepreneurial activity observed in U.S. data, we specify the $\Gamma(a)$ distribution to be Pareto. This has the computational advantage of introducing only one calibration target, namely the shape parameter, which we denote $\kappa{ }^{19}$ Recall that we restrict the innovation ability distributions to be identical across the native- and foreign-born. As a result, nativity differences in sorting across innovation and managerial employment are reflected in the productivity parameters $f^{\text {nat }}$ and $f^{f o r}$. For the sake of consistency, we specify $\Upsilon(u)$ to also be Pareto, with corresponding shape parameter $\nu$.

Given this, we jointly calibrate the following six parameters: the production share parameters $\alpha$ and $\lambda$, the shape parameters $\nu$ and $\kappa$, and the innovation productivity parameters $f^{n a t}$ and $f^{f o r}$ as follows. In order to identify these we specify that along the BGP, the model matches the following six moments from the 1980 census data. First, we match three "quantity moments." Given the results of Section 2, we calibrate the BGP values $s^{h i}=0.896$ and $s^{\text {for }}=0.819$ to match the fraction of non-routine cognitive workers in managerial (i.e. non-STEM) occupations, for the native- and foreign-born, respectively. We set $s^{l o}=0.2$ to match the fraction of lowskilled workers that work in service (i.e. non-routine manual) occupations. The remaining three moments relate to prices: (i) a share of total labor income paid to low-skilled (routine and service) labor of $47 \%$, (ii) a median routine-to-service occupation wage ratio of 1.75 , and (iii) a median managerial-to-routine occupation wage ratio of 1.6 .

This leaves the two elasticity parameters in production to be specified. Given the nature of our results, we set $\rho=0.995$. That is, we set the elasticity of substitution between automation technology and routine labor as close to infinite as (computationally) possible; this allows the model to maximize the effect of increased innovation and NBTC on the demand for routine labor. Finally, we set $\sigma=0.5$. In numerical experiments, we find that our results are extremely robust to the choice of this parameter.

\footnotetext{
${ }^{19}$ The scale or location parameter of the Pareto distribution is simply a normalization relative to $f^{\text {nat }}$ and $f^{\text {for }}$, for the purposes of calibration.
} 


\subsection{Nature of the Experiments}

As discussed above, the period since 1980 is not well characterized as displaying balanced growth. The phenomenon of job polarization has meant that employment allocations have not been constant: the share of employment in routine occupations has been falling, while the shares in non-routine cognitive and service occupations has been rising. Moreover, inequality between high- and low-skill wages has increased; more recently, routine and service occupation wages have converged (see Acemoglu and Autor (2011).)

From the perspective of the model, the past 35 years has been a period of unbalanced growth. In particular, NBTC and the accumulation of automation technology has led to a inward shift in the demand for routine labor, and an outward shift in the demand for high-skilled labor, all else equal. Moreover, rising educational attainment has meant a shift in the composition of labor supply toward high-skilled workers, and immigration policy has led to a rise in the foreign-born share of the high-skilled population.

As such, we conduct a series of quantitative experiments in the model to isolate the role of immigration for the evolution of the economy during this unbalanced growth period. In our experiments we assume the economy was on a BGP in 1980 and then hit by a number of shocks that we specify below. After the arrival of the shocks, we track the perfect foresight transition path of the economy to a new BGP. We specify that the economy arrives at the new BGP in the year 2070, 90 years after the arrival period of the shock. ${ }^{20}$

Specifically, we assume that in 1980 the economy is hit with two shocks. First, we allow the fraction $\mu^{\text {for }}$ to increase at a constant rate; this growth is specified so that after 30 years of growth, the fraction of high-skilled, foreign-born workers matches that observed in 2010 in the U.S. data. Second, we allow for a one-time increase in the innovation productivity, $f^{\text {for }}$, upon impact of the shock. This causes foreign-born workers to sort more heavily into innovation as opposed to managerial labor. We do this in a manner that replicates the increase in the tendency of high-skilled, non-routine cognitive workers to work in STEM occupations observed among the foreign-born between 1980 and 2010, as reported in the bottom panel of Table 2 .

As discussed in subsection 3.3, both of these changes (increasing $\mu^{\text {for }}$ and $f^{\text {for }}$ ) increase the number of innovators in the economy, and results in an endogenous rise in the growth rate of ideas. Our experiment causes $g^{n}$ to rise while leaving the growth rates of labor-augmenting productivity $(z)$ and the service occupation productivity $\left(w_{S}\right)$ unchanged at their previous BGP value. The new BGP is attained in 2070 when the growth rates of $z$ and $w_{S}$ make a one-time increase from $g$ to the endogenously determined value of $g^{n}$ in that period. From 2070 onward,

\footnotetext{
${ }^{20}$ In principle, the results of the experiment depend on the date at which the new BGP is attained, because agents in the model operate with perfect foresight. However, in experiments not reported here, we find that the results for the transition path are incredibly insensitive to the choice of this date. For instance, when we set the date to 2010, the results for the period between 1980 and 2010 are surprisingly similar to the case reported here, with the terminal date set to 2070 .
} 
Figure 2: High-Skilled Immigration Experiment

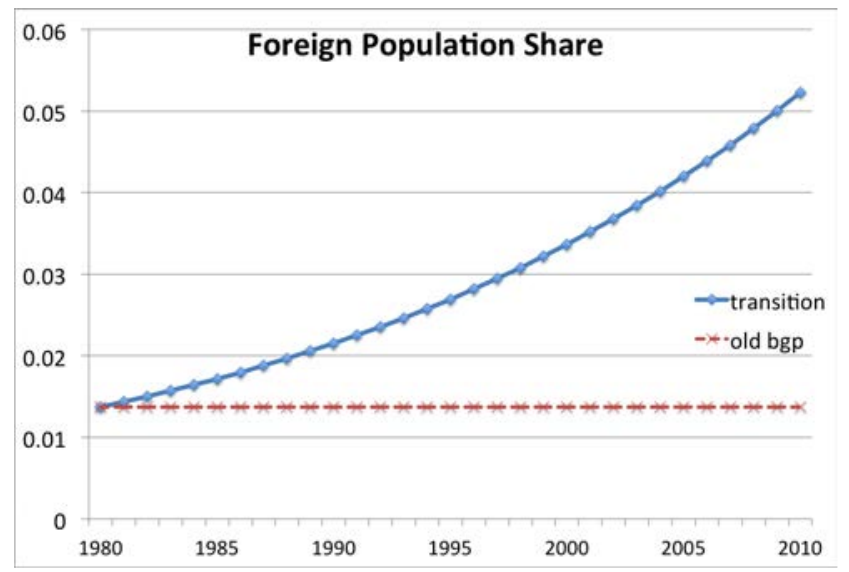

Notes: The red dashed line indicates the time series under the original balanced growth path; the blue line represents the immigration experiment. See text for details.

$\mu^{\text {for }}$ becomes constant.

\subsection{Results}

Figure 2 presents the foreign-born population share for the period 1980 to 2010 . In all figures, the red dashed line indicates the time series under the original BGP, while the blue line represents the immigration experiment detailed in the previous subsection. By construction, the values for 1980 and 2010 along the experiment's transition path correspond with the values observed in the 1980 Census and 2010 ACS data, representing a four-fold increase. Recall that the foreign-born population in the model represents only foreign-born, high-skilled employment.

In the upper-left panel of Figure 3, we present the fraction of high-skilled workers who sort into innovation $\left(1-s^{\text {for }}\right)$ among the foreign-born. By construction, this increases as observed in the U.S. data, due to the increase in foreign-born innovation productivity. The upper-right panel presents the same variable for the native-born. In response to the increase in the number of foreign-born innovators, the fraction of native-born who sort into innovation falls.

Though this effect on native-born innovation is quantitatively small, it is instructive to understand the force generating it. Native sorting into innovation falls, despite production of new ideas being linear in the number of innovators; that is, the fall occurs despite innovation productivity of the native-born, $f^{n a t}$, remaining unchanged in the experiment. Instead, the fall is due to the general equilibrium effect on the real interest rate.

Specifically, the increase in high-skilled immigration endogenously increases economic growth. This is evidenced in the middle row of Figure 3. During the first 30 years of transition, the growth rate of ideas and consumption are higher than under the original BGP (both variables are normalized to one in 1980). Because the representative household has concave preferences, it desires 
Figure 3: High-Skilled Immigration Experiment
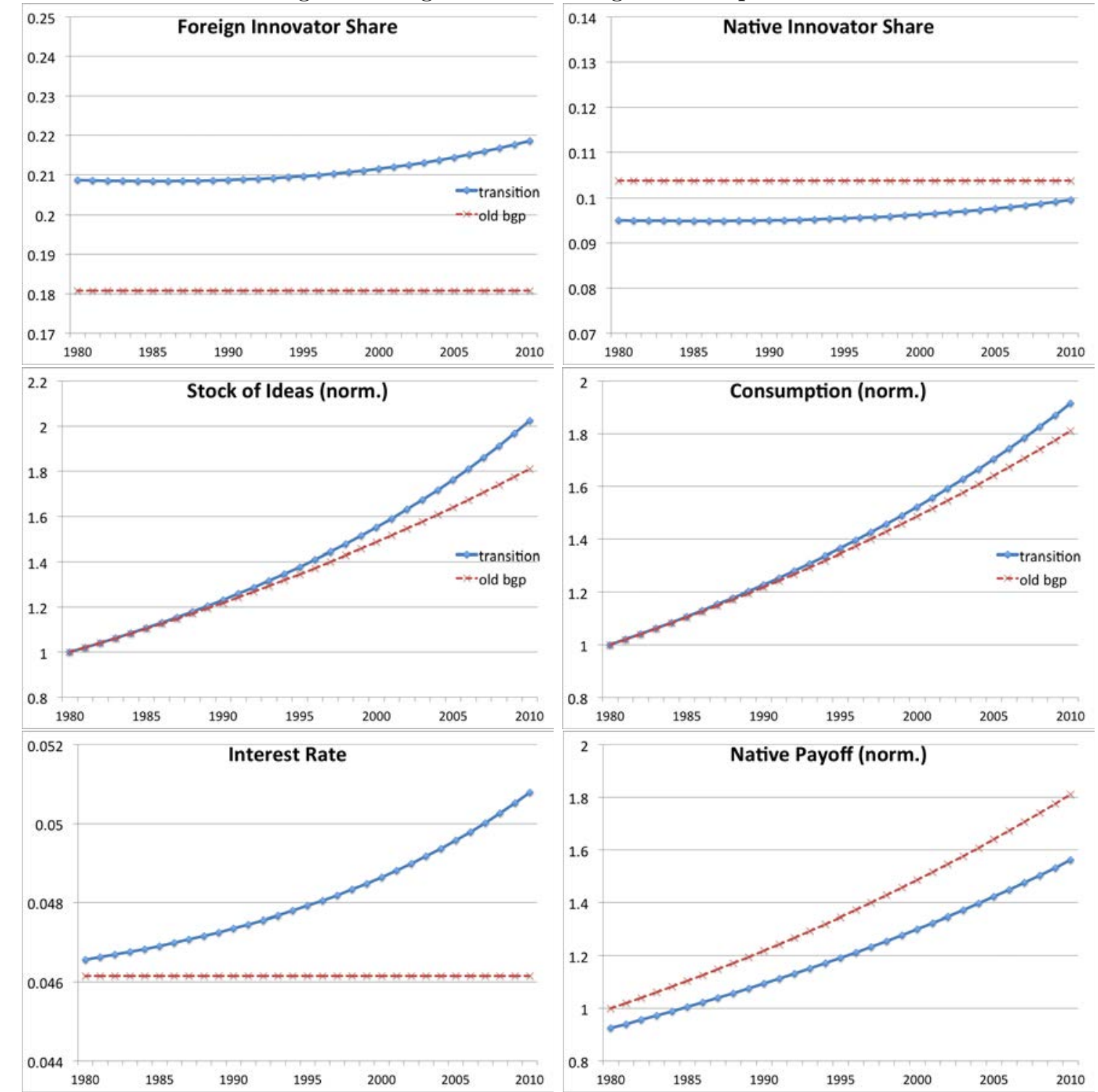

Notes: The red dashed line indicates the time series under the original balanced growth path; the blue line represents the immigration experiment. See text for details.

to smooth consumption intertemporally and transfer some of the additional future consumption growth forward in time. Obviously, this reallocation of consumption is not possible in equilibrium (of our closed economy model). This necessitates an increase in the real interest rate or return to saving, as displayed in the bottom-left panel of Figure 3.

The increase in the interest rate, in turn, affects the equilibrium return to innovation. Recall that the payoff to innovation, displayed in the bottom-right panel, is the present value of the future profit stream accruing to the generated ideas. This is summarized by equation (23), which 
we reproduce here:

$$
w_{M t}=a_{t}^{n a t *} f^{n a t} n_{t} \sum_{i=1}^{\infty}\left[\frac{\pi_{t+i}}{\prod_{j=1}^{i} R_{t+j}}\right] .
$$

Higher real interest rates mean that future profits are discounted more heavily. All else equal, sorting into innovation becomes more selective; the ability level at which high-skilled nativeborn workers are indifferent between working in management and innovation must rise. Since the high-skilled native-born workers did not experience a shock to their innovation productivity, less of them sort into innovation (though, as stated above, the effective is quantitatively small).

The upper and middle rows of Figure 4 present the time series for managerial labor. As the population of high-skilled, foreign-born workers increases, so too does the number of foreign-born managers. ${ }^{21}$ By 2010, this increase is quantitatively large. The number of native-born managers also increases due to the change in occupational sorting described above, though again, this is quantitatively small. As a result, total employment in the managerial occupation increases by approximately $20 \%$ over the 30 year period, as displayed in the middle-left panel, due largely to the foreign-born increase. As a result of this immigration-induced increase in the supply of labor, the managerial wage rate falls relative to the original BGP. This is displayed in the middle-right panel.

The bottom row of Figure 4 present the time series for routine labor. Though the effect is quantitatively small, increased high-skilled immigration, has the effect of increasing employment in routine occupations. That is, during the 1980 to 2010 transition period of our model's experiment, high-skilled immigration has not been responsible for a decrease in routine employment among the native-born. And as indicated in the bottom-right panel, the increase in the high-skilled foreign-born workforce has not led to a fall in the wage earned by routine workers. Because the quantitative effect is small, we plot this as a $l o g$ deviation from the original BGP. Nonetheless, the result of the immigration experiment is to increase the marginal product of routine labor.

To understand this, note that an increase in high-skilled immigrants has two effects on the demand for routine labor. First, because of the increase in the number of innovators, there is an increase in the growth rate of ideas and an increase in the accumulation of automation technology. Because automation technology and routine labor are substitutes in production, this lowers routine labor demand, as derived in equation (12). However, high-skilled immigrants also work as managers. Though the foreign-born sort more intensively into innovation relative to the native-born, the majority are employed in managerial occupations. Hence, the increase in immigration increases managerial labor. Because managerial labor and routine tasks - and, therefore, routine labor - are complements in production, this raises routine labor demand. This complementarity effect dominates the substitution effect, resulting in an equilibrium increase in employment and wages in routine occupations.

\footnotetext{
${ }^{21}$ Note that foreign-born managerial labor actually falls slightly in the very first period, relative to the original BGP. This is due to the increased sorting into innovation.
} 
Figure 4: High-Skilled Immigration Experiment
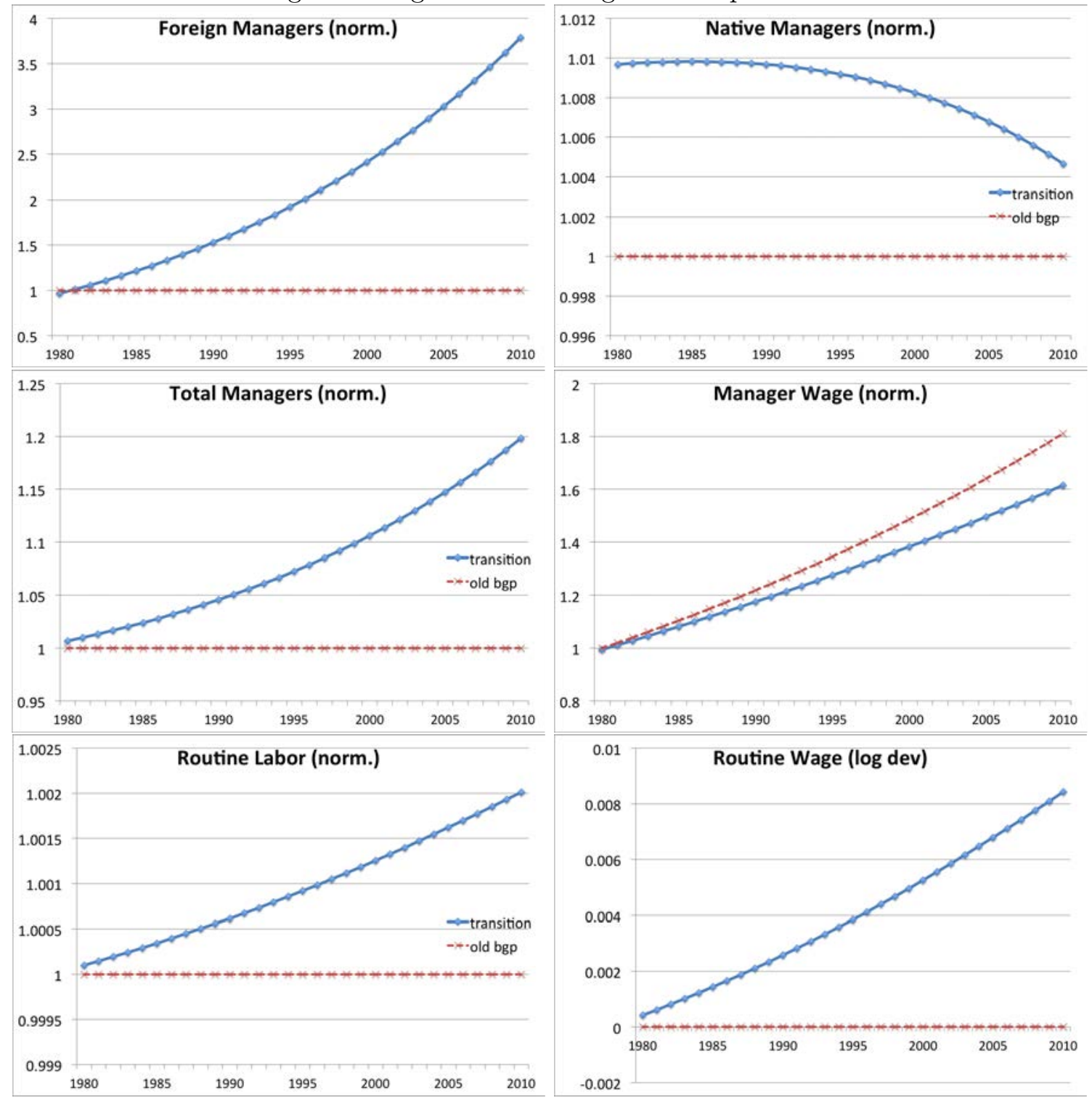

Notes: The red dashed line indicates the time series under the original balanced growth path; the blue line represents the immigration experiment. See text for details.

As a result, the model predicts that increased high-skilled immigration has led to a narrowing of inequality between low- and high-skilled workers. This is displayed in Figure 5. The upper-left panel plots the ratio of wages between routine and managerial labor; this has been normalized so that its value in the original BGP is one. Evidently, increased immigration causes this ratio to rise, shrinking the wage gap between routine workers and managers.

As an alternative measure of inequality, the upper-right panel displays the ratio of labor 
Figure 5: High-Skilled Immigration Experiment
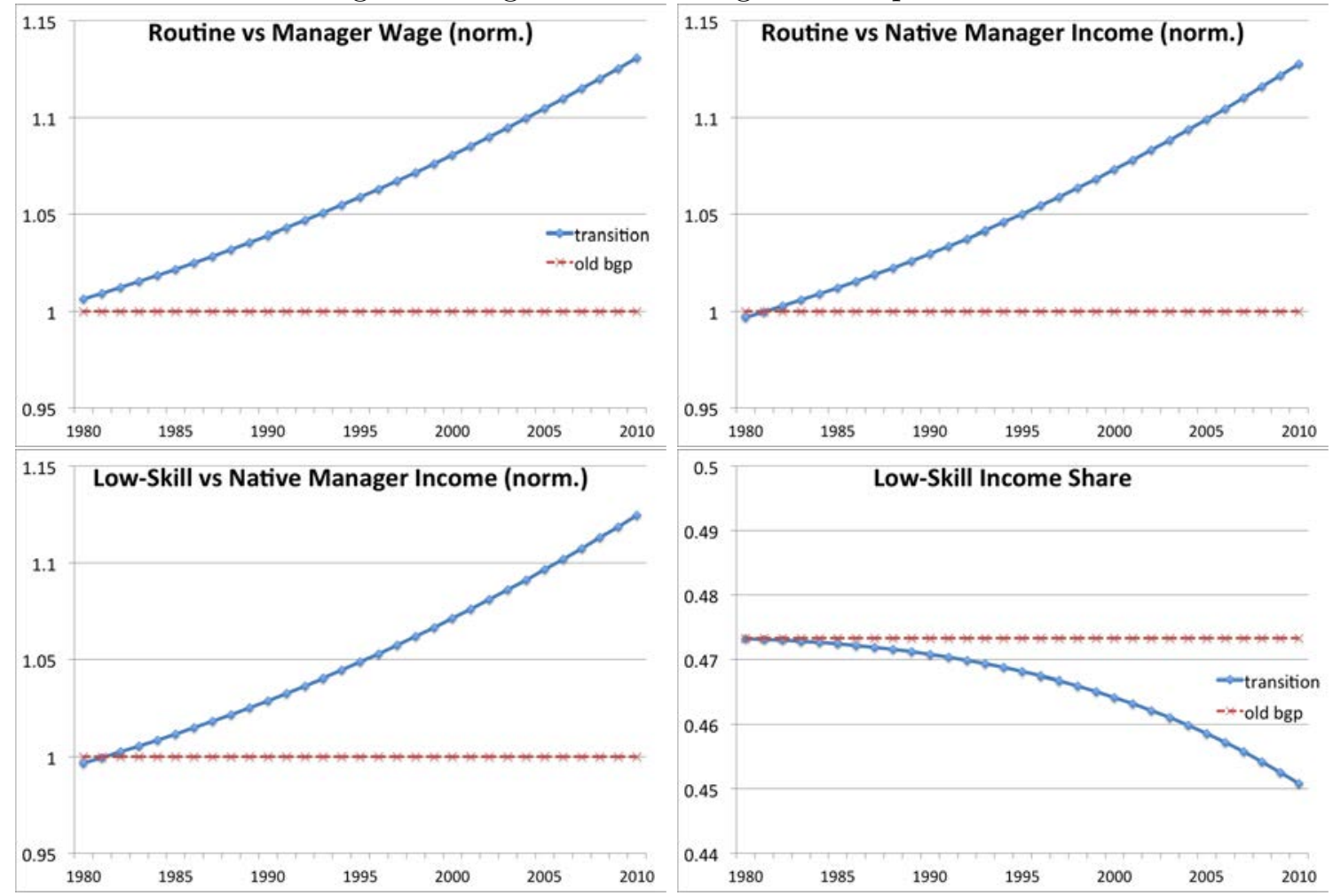

Notes: The red dashed line indicates the time series under the original balanced growth path; the blue line represents the immigration experiment. See text for details.

income earned by native-born routine workers to managers, specifically:

$$
\frac{w_{R t} \int_{u_{t}^{*}}^{\infty} u d \Upsilon(u)(1-\phi)}{w_{M t} \phi s_{t}^{h i}} .
$$

This differs from the ratio of wages, $w_{R t} / w_{M t}$, in that it accounts for changes in routine and managerial employment among the native-born, via changes in occupational sorting. ${ }^{22}$ While this statistic is conceptually different, it generates decreasing inequality that is quantitatively very similar to that observed in the wage gap. ${ }^{23}$

The lower-left panel displays the ratio of labor income earned by all low-skilled workers to native-born managers. That is, it adds the income earned by service occupation workers to the numerator of equation (30). Relative to (30), this provides greater scope for worsened relative outcomes for the low-skilled, as employment gains in routine occupations come out of employment in the service occupation. Nonetheless, the change in this statistic is quantitatively very similar to those discussed above. Finally, the bottom-right panel displays the share of

\footnotetext{
${ }^{22}$ In addition, increases in routine employment are drawn from the lower end of the skill distribution, $\Upsilon(u)$, from workers who previously sorted into the service occupation.

${ }^{23}$ In the first two periods of the experiment, the income ratio falls relative to the original BGP; this is due primarily to the larger increase manager employment relative to routine employment among the native-born. However, as the transition progresses, this quickly reverses.
} 
total income accruing to low-skilled (native-born) labor. Between 1980 and 2010, this falls only modestly by about $2 \mathrm{pp}$; this is primarily a mechanical result of the fact that total low-skilled employment is constant while the experiment adds only high-skilled foreign-born workers over time.

\subsection{Further Analysis}

In this section, we provide analytical results to illustrate that relative to the $1980 \mathrm{BGP}$, the increase in high-skilled immigration has a quantitatively small effect on non-routine-biased technical change. As a result, early in the transition path to a new BGP, the substitution effect of increased automation technology on the demand for routine labor is small.

To see this, consider equation (27) describing the equilibrium growth rate of ideas, where we have used the fact that $\Gamma(a)$ is a Pareto distribution with shape parameter $\kappa$ :

$$
g_{t+1}^{n}=\mu^{n a t} \phi f^{n a t} \bar{\kappa}\left(a_{t}^{n a t *}\right)^{1-\kappa}+\mu^{\text {for }} f^{\text {for }} \bar{\kappa}\left(a_{t}^{\text {for } *}\right)^{1-\kappa},
$$

where $\bar{\kappa} \equiv \frac{\kappa}{\kappa-1}$. Log-linearizing this equation obtains:

$$
\begin{array}{r}
\hat{g}^{n}=\frac{\mu^{\text {nat }} \phi f^{n a t} \bar{\kappa}\left(a^{n a t *}\right)^{1-\kappa}}{\mu^{\text {nat }} \phi f^{n a t} \bar{\kappa}\left(a^{n a t *}\right)^{1-\kappa}+\mu^{\text {for }} f^{\text {for }} \bar{\kappa}\left(a^{\text {for } *}\right)^{1-\kappa}}\left[\hat{\mu}^{\text {nat }}+\hat{\phi}+\hat{f}^{\text {nat }}+(1-\kappa) \hat{a}^{\text {nat } *}\right]+ \\
\frac{\mu^{\text {for }} f^{\text {for }} \bar{\kappa}\left(a^{\text {for } *}\right)^{1-\kappa}}{\mu^{\text {nat }} \phi f^{n a t} \bar{\kappa}\left(a^{\text {nat } *}\right)^{1-\kappa}+\mu^{\text {for }} f^{\text {for }} \bar{\kappa}\left(a^{\text {for } *}\right)^{1-\kappa}}\left[\hat{\mu}^{\text {for }}+\hat{f}^{\text {for }}+(1-\kappa) \hat{a}^{\text {for } *}\right] .
\end{array}
$$

In our immigration experiment, we leave the measure of high-skilled native-born workers and native productivity unchanged $\left(\hat{\mu}^{n a t}=\hat{\phi}=\hat{f}^{n a t}=0\right.$ ). Moreover, as displayed in Figure 3, occupational choice among the native-born hardly changes; this implies that the native cutoff ability hardly changes $\left(\hat{a}^{n a t *} \approx 0\right)$.

As such, we focus our attention on the second term in equation (31), and approximate it as:

$$
\hat{g}^{n} \approx \frac{\mu^{\text {for }} f^{\text {for }}\left(a^{\text {for } *}\right)^{1-\kappa}}{\mu^{\text {nat }} \phi f^{\text {nat }}\left(a^{\text {nat } *}\right)^{1-\kappa}+\mu^{\text {for }} f^{\text {for }}\left(a^{\text {for } *}\right)^{1-\kappa}}\left[\hat{\mu}^{\text {for }}+\hat{f}^{\text {for }}+(1-\kappa) \hat{a}^{\text {for } *}\right] .
$$

Under the Pareto distribution, $\left(a^{*}\right)^{-\kappa}$ is the fraction of high-skilled workers who sort into innovation. Using this and equation (29), (32) becomes:

$$
\hat{g}^{n} \approx \varphi\left[\hat{\mu}^{f o r}+\hat{f}^{\text {for }}+(1-\kappa) \hat{a}^{f o r *}\right]
$$

where:

$$
\varphi \equiv \frac{\mu^{\text {for }}\left(a^{\text {for } *}\right)^{-\kappa}}{\mu^{\text {for }}\left(a^{\text {for } *}\right)^{-\kappa}+\mu^{\text {nat }} \phi\left(a^{\text {nat } *}\right)^{-\kappa}} .
$$

Note that $\varphi$ is simply the foreign-born share of innovators.

Calculated at 1980 BGP values, $\varphi=0.122$. Hence, to a log-linear approximation, the impact of high-skilled immigration on the growth rate of ideas - that is, the pace of NBTC - is small. 
For instance, suppose we were to consider an immediate doubling of the measure of foreign-born workers in 1980 (i.e. $\hat{\mu}^{\text {for }}=1$ ); this is large given that it took 15 years for the model economy to experience the same sized increase (as displayed in Figure 2). Using equation (33), this would increase $g^{n}$ from the original BGP value of $2 \%$ to $2.224 \% .{ }^{24}$ This illustrates how, during the 1980 to 2010 period under consideration, the substitution effect of automation technology growth on routine labor demand is dominated by the direct complementarity effect of increased managerial labor supply, brought about by high-skilled immigration.

Note, however, that the relative importance of the substitution and complementarity effects depends on the time horizon under consideration. The strength of each grows at a different rate in our experiment. Consider the complementarity effect of managerial labor. In the long run, the growth rate of managers is bounded above by the (constant) growth rate of high-skilled immigration. By contrast, the substitution effect is governed by the stock of ideas. The growth rate of ideas, displayed in equation (27), depends on the level of high-skilled labor, given our Romer (1990)-style specification of technical change. Hence, the direct effect of immigration implies that the growth rate of ideas and automation technology is increasing over time.

This is illustrated in Figure 6, where we plot the entire 90-year transition path of the immigration experiment. Recall that the experiment involves growth of the high-skilled, foreign-born workforce at a constant rate (which generates increasing idea growth, $g^{n}$ ), leaving the growth rate of the other forms of technology (specifically, $z$ and $w_{S}$ ) constant. In the 90th period, immigration stops and the growth rates of $z$ and $w_{S}$ make a one-time increase to the endogenous value of $g^{n}$ so that the economy enters a new BGP.

As the top row of Figure 6 makes clear, the stock of ideas exhibits much greater growth than the number of managers in the very long run. The substitution effect of automation technology on routine labor demand eventually dominates the complementarity effect of increased managerial labor. The middle row displays routine employment and the routine wage. Both display about 55 periods of growth during the experiment. However, they begin to decline in about 2035, cross below the values implied by the original BGP in about 2050, and fall precipitously thereafter. The bottom row displays two measures of inequality between low- and high-skilled workers. Consider, for instance, the routine-to-manager wage ratio. If high-skilled immigration growth and NBTC were to continue as predicted by the model until 2070, this wage ratio would be approximately one-third of its value in the 1980 BGP.

Hence, the impact of high-skilled immigration on polarization and wage inequality are evident only in the very long run. However, there are many good reasons to question the predictions from this experiment for outcomes 50 to 60 years hence. This is because of the stark assumptions made in the analysis of the specific model experiment. For instance, the experiment assumes

\footnotetext{
${ }^{24}$ Of course, the accuracy of this log-linear approximation is compromised for such a large shock, $\hat{\mu}^{\text {for }}$. Note also that our experiment discussed in the previous two subsections also considered a positive shock, $\hat{f}^{\text {for }}>0$; however, the equilibrium effect of this is to induce an offsetting fall, $\hat{a}^{\text {for } *}<0$. All things considered, the nature of the result remains that the effect of immigration on NBTC is small.
} 
Figure 6: High-Skilled Immigration Experiment: Extended

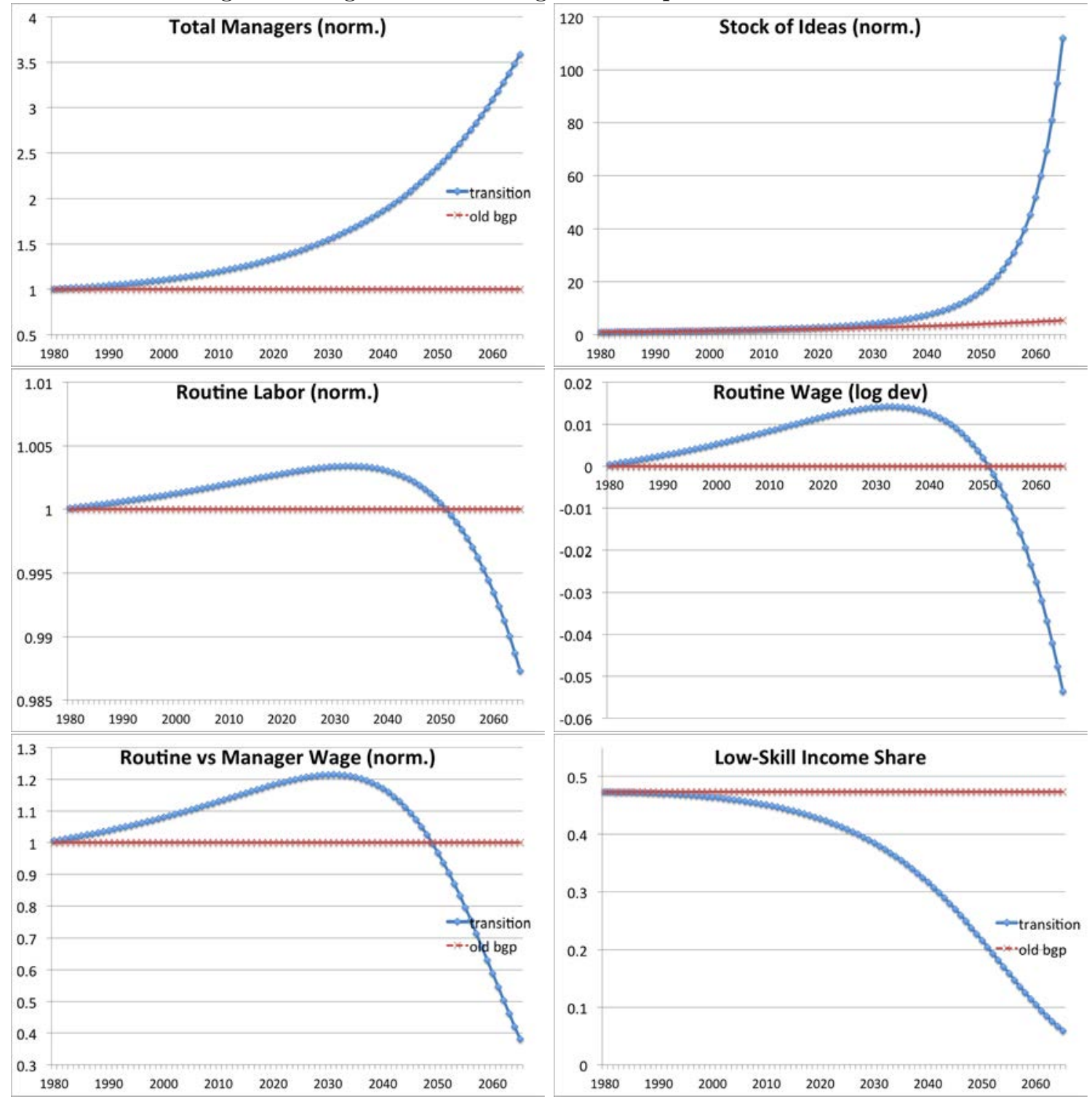

Notes: The red dashed line indicates the time series under the original balanced growth path; the blue line represents the immigration experiment. See text for details.

constant growth of the high-skilled foreign-born population over 90 years, at the substantial growth rates observed between 1980 and 2010. Future immigration policy is obviously uncertain. In addition, it assumes that the direction of technical change via innovation remains non-routinebiased over the 90 year period. That is, innovative activity augments automation technology leaving, for instance, the path of labor-augmenting technology unchanged. While this may be a good representation of the past 30 years, it may not remain the case for the next 60 . Finally, the model assumes Romer (1990)-style scale effects on the growth of non-routine-biased ideas. Augmenting the model to diminish or eliminate these scale effects would weaken the long-run substitution of automation technology for routine labor. 
As such, we view the predictions of Figure 6 as uncertain and representing an upper bound of the effects of high-skilled immigration on increasing inequality. In terms of the 1980-2010 experience, the model indicates that high-skilled immigration has, in fact, reduced inequality.

\section{Conclusion}

In the last 30 to 40 years, immigration has constituted an important source of growth in highskilled employment, innovation, and productivity in the U.S. At the same time, the U.S. has experienced technical change that is non-routine-biased, allowing technology to substitute for labor in performing routine tasks, leading to job polarization and wage polarization in the labor market.

In this paper, we study the role of high-skilled immigration in accounting for these changes in the occupational-skill distribution and wage inequality. We do so in a general equilibrium model featuring endogenous non-routine-biased technical change. We use this model to quantify the impact of high-skilled immigration, and the increasing tendency of the foreign-born to work in innovation, on the pace of technical change, the polarization of employment opportunities, and the evolution of wage inequality since 1980. We find that high-skilled immigration has led to a narrowing of inequality. 


\section{References}

Acemoglu, D. and D. Autor (2011). Skills, tasks and technologies: Implications for employment and earnings. In O. Ashenfelter and D. Card (Eds.), Handbook of Labor Economics, Volume 4B, Chapter 12, pp. 1043-1171. Elsevier.

Acemoglu, D. and P. Restrepo (2015). The race between man and machine: Implications of technology for growth, factor shares and employment. Working paper, MIT.

Autor, D. H., D. Dorn, and G. H. Hanson (2015). Untangling trade and technology: Evidence from local labour markets. Economic Journal 125, 621-646.

Autor, D. H., F. Levy, and R. J. Murnane (2003). The skill content of recent technological change: An empirical exploration. Quarterly Journal of Economics 118(4), 1279-1333.

Blinder, A. (1973). Wage discrimination: Reduced form and structural estimates. Journal of Human Resources 8, 436-455.

Caselli, F. (2015). Experience-biased technical change. CEPR Discussion Paper 10752.

Chiswick, B. and S. Taengnoi (2007). Occupational choice of high skilled immigrants in the United States. International Migration 45(5), 3-34.

Cortes, G. M., N. Jaimovich, C. J. Nekarda, and H. E. Siu (2015). The micro and macro of disappearing routine jobs: a flows approach. Working paper, UBC.

Cortes, G. M., N. Jaimovich, and H. E. Siu (2016). Disappearing routine jobs: Who, how, and why? Working paper, USC Marshall School.

Firpo, S., N. M. Fortin, and T. Lemieux (2011). Occupational tasks and changes in the wage structure. Working paper, UBC.

Goos, M. and A. Manning (2007). Lousy and lovely jobs: The rising polarization of work in britain. Review of Economics and Statistics 89(1), 118-133.

Goos, M., A. Manning, and A. Salomons (2014). Explaining job polarization: Routine-biased technological change and offshoring. American Economic Review 104(8), 2509-26.

Grieco, E. M., E. Trevelyan, L. Larsen, Y. D. Acosta, C. Gambino, P. de la Cruz, T. Gryn, and N. Walters (2012). The size, place of birth, and geographic distribution of the foreign-born population in the United States: 1960 to 2010. Population Division Working Paper 96, U.S. Census Bureau.

Hanson, G. H. and M. J. Slaughter (2016). High-skilled immigration and the rise of STEM occupations in US employment. NBER Working Paper No. 22623. 
Hunt, J. (2011). Which immigrants are most innovative and entrepreneurial? distinctions by entry visa. Journal of Labor Economics 29(3), 417-457.

Hunt, J. and M. Gauthier-Loiselle (2010). How much does immigration boost innovation? American Economic Journal: Macroeconomics 2(2), 31-56.

Jaimovich, N. and H. E. Siu (2012). Job polarization and jobless recoveries. NBER Working Paper 18334.

Jaimovich, N. and H. E. Siu (2015). Jobless recoveries. Third Way NEXT.

Jung, J. and J. Mercenier (2014). Routinization-biased technical change and globalization: Understanding labor market polarization. Economic Inquiry 52(4), 1446-1465.

Kerr, S. P., W. R. Kerr, and W. F. Lincoln (2013). Skilled immigration and the employment structures of U.S. firms. NBER Working Paper 19658.

Kerr, W. (2013). U.S. high-skilled immigration, innovation, and entrepreneurship: Empirical approaches and evidence. NBER Working Paper 19377.

Kerr, W. and W. Lincoln (2010). The supply side of innovation: H-1B visa reforms and U.S. ethnic invention. Journal of Labor Economics 38(3), 473-508.

Levy, F. and R. J. Murnane (2014). Dancing with robots: Human skills for computerized work. Third Way NEXT.

Oaxaca, R. (1973). Male-female wage differentials in urban labor markets. International Economic Review 14, 693-709.

Peri, G. (2012). The effect of immigration on productivity: Evidence from U.S. states. Review of Economics and Statistics 94(1), 348-358.

Peri, G., K. Shih, and C. Sparber (2015). Stem workers, h-1b visas, and productivity in us cities. Journal of Labor Economics 33(S1), S225-255.

Peri, G. and C. Sparber (2011). Highly educated immigrants and native occupational choice. Industrial Relations 50(3), 385-411.

Romer, P. M. (1990). Endogenous technological change. Journal of Political Economy 98(5), S71-102.

Ruggles, S., J. T. Alexander, K. Genadek, R. Goeken, M. B. Schroeder, and M. Sobek (2010). Integrated Public Use Microdata Series: Version 5.0 [machine-readable database].

Violante, G. L. (2008). Skill-biased technical change. In S. N. Durlauf and L. E. Blume (Eds.), The New Palgrave Dictionary of Economics (Second ed.). Palgrave Macmillan. 